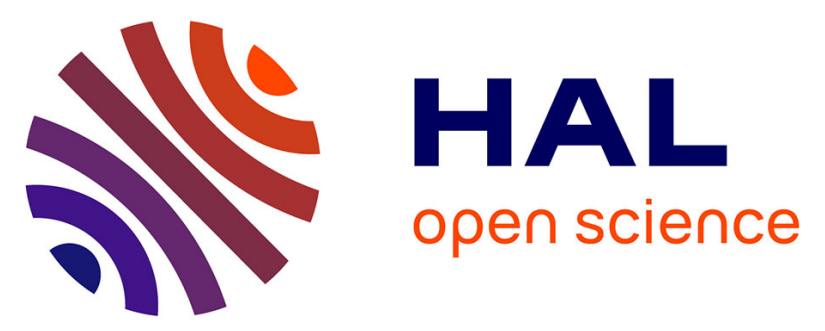

\title{
Rationale and design of the CANARI study: a case-control study investigating the association between prostate cancer and 5-alpha-reductase inhibitors for symptomatic benign prostate hypertrophy by linking SNIIRAM and pathology laboratories in a specific region in France
}

Lucie-Marie Scailteux, Frédéric Balusson, Sébastien Vincendeau, Nathalie Rioux-Leclercq, Emmanuel Nowak

\section{To cite this version:}

Lucie-Marie Scailteux, Frédéric Balusson, Sébastien Vincendeau, Nathalie Rioux-Leclercq, Emmanuel Nowak. Rationale and design of the CANARI study: a case-control study investigating the association between prostate cancer and 5-alpha-reductase inhibitors for symptomatic benign prostate hypertrophy by linking SNIIRAM and pathology laboratories in a specific region in France. Fundamental \& Clinical Pharmacology, 2018, 32 (1), pp.120-129. 10.1111/fcp.12320 . hal-01734950

HAL Id: hal-01734950

https://hal-univ-rennes1.archives-ouvertes.fr/hal-01734950

Submitted on 15 Mar 2018

HAL is a multi-disciplinary open access archive for the deposit and dissemination of scientific research documents, whether they are published or not. The documents may come from teaching and research institutions in France or abroad, or from public or private research centers.
L'archive ouverte pluridisciplinaire HAL, est destinée au dépôt et à la diffusion de documents scientifiques de niveau recherche, publiés ou non, émanant des établissements d'enseignement et de recherche français ou étrangers, des laboratoires publics ou privés. 
DR. LUCIE-MARIE SCAILTEUX (Orcid ID : 0000-0001-7047-9107)

Article type : Original Article

Rationale and design of the CANARI study: a case-control study investigating the association between prostate cancer and 5 alpha-reductase inhibitors for symptomatic benign prostate hypertrophy by linking SNIIRAM and pathology laboratories in a specific region in France

Running title: Prostate cancer risk and 5alpha-reductase inhibitors

$$
\begin{aligned}
& \text { Lucie-Marie SCAILTEUX }^{\mathrm{a}, \mathrm{b}, *} \text {, Frédéric BALUSSON }{ }^{\mathrm{a}, \mathrm{b}} \text {, Sébastien VINCENDEAU }{ }^{\mathrm{c}, \mathrm{d}} \text {, } \\
& \text { Nathalie RIOUX-LECLERCQ }{ }^{\text {e,f }} \text {, Emmanuel NOWAK }{ }^{\text {g,h }}
\end{aligned}
$$

a. Centre Régional de Pharmacovigilance, de Pharmaco-épidémiologie et d'information sur le médicament, CHU Rennes, France

b. UPRES-EA 7449 « REPERES », Université de Rennes 1 et EHESP, France

c. Service d'Urologie, CHU Rennes, France

d. INSERM CIC 1414, CHU de Rennes, France

e. Service d'Anatomie et Cytologie Pathologiques, CHU Rennes, Université de Rennes 1, France

f. IMR 1085 - IRSET, Université Rennes 1, France

g. CHU de Brest

h. Université de Brest, INSERM CIC 1412, IFR 148, France

This article has been accepted for publication and undergone full peer review but has not been through the copyediting, typesetting, pagination and proofreading process, which may lead to differences between this version and the Version of Record. Please cite this article as doi: $10.1111 /$ fcp. 12320

This article is protected by copyright. All rights reserved. 
${ }^{*}$ Corresponding author : Lucie-Marie SCAILTEUX

Pharmacovigilance, Pharmacoepidemiology and Drug Information Center

Pontchaillou Hospital, 2 rue Henri Le Guilloux, 35000, Rennes, France

luciemarie.scailteux@chu-rennes.fr

\section{ABSTRACT}

Benign prostate hypertrophy (BPH) could be associated with low urinary symptoms requiring medical treatment: 5 alpha-reductase inhibitors (5-ARI) or a-blockers. Two clinical trials investigating 5 -ARI use in prostate cancer (PCa) primary prevention highlighted a potential safety signal with an increased risk of high grade PCa. Later observational studies failed to show similar results but have some limits.

The present paper focuses on describing the protocol of the CANARI study and its feasibility, as regards the matching process of two pseudo-anonymous databases.

The study concerned patients living in the Brittany region (France) between 2010 and 2013. We designed a case-control study nested within a cohort of men treated by medical drugs licensed for symptomatic BPH between 2010 and 2011. Cases were patients with incident PCa diagnosed between 2012 and 2013 identified through French Health database (SNIIRAM). Gleason score was searched through Brittany pathology laboratories. Controls were patients without PCa diagnosis.

Local pathology laboratories database was constituted in Brittany, gathering Gleason scores. No unique identification number is available in France; linkage of SNIIRAM and Brittany pathology laboratories database was made by deterministic matching.

We matched 859 cases to Gleason grading ( 119 had Gleason score $\geq 8$ and 740 had Gleason < 8); around $22 \%$ of cases received 5 -ARI and $78 \% \alpha$-blockers or phytotherapy.

The CANARI study investigated in a population of men treated for BPH the risk of PCa with 5-ARI, according to Gleason grade thanks to SNIIRAM database enriched by local pathological results.

This article is protected by copyright. All rights reserved. 
Key words: 5 alpha reductase inhibitors, prostate cancer, Gleason score, deterministic linkage, SNIIRAM database, pathology database.

\section{INTRODUCTION}

Benign prostate hypertrophy (BPH) is a frequent affection in men after 40 year-old with a prevalence increasing with age. In France, in the early 2000's, $58 \%$ of men of 55 to 70 year-old consulting their general practitioner had a BPH (prevalent and incident disease) [1]. Moderate-to-severe low urinary tract symptoms (LUTS) are frequently associated with BPH, in 14 to $21 \%$ of French men after 50 year-old $[2,3]$. Inducing a potential decrease of quality of life, LUTS need a medical treatment, mainly 5a-reductase inhibitors (5-ARI) or $\alpha$-blockers; phytotherapy is a little bit used therapeutic option, associated with limited efficacy [4-6]. Surgery is indicated in case of non-response to medical treatment or in front of bothersome or severe symptoms and complications [4].

Testosterone is involved in prostate growth after conversion in dihydrotestosterone (DHT) thanks to 5a-reductase (5AR) enzyme (existing through two isoforms 5AR-1 and 5AR-2 (13)). Some authors have shown through human prostate tissue study that mRNA expression of both isoforms appeared increased in BPH, and that 5AR-1 mRNA expression was increased in prostate cancer (PCa) (14). Currently, two 5-ARIs are available in treatment of BPH: finasteride which inhibits 5ARI-2 and dutasteride which inhibits both isoforms, leading to prostate epithelial cells apoptosis. a-blockers induce a ball tone decrease and make easier the urine discharge, and appear as the first line treatment in patients with LUTS owing to rapid onset of action. Some studies have shown that contrary to 5-ARI, $\alpha$-blockers did not reduce the prostate size (idem for phytotherapy) nor the longterm risk (> 1 year) of acute urinary retention, patients must also being surgically treated [7-10]. Owing to the European Association of Urology (EAU), 5-ARI should only be recommended in men with annoying moderate-to-severe LUTS and enlarged prostate (volume $>40 \mathrm{ml}$ ) or elevated prostate specific antigen (PSA) level $(>1.4 \mathrm{ng} / \mathrm{ml}$ ) where they induce a 18 to $28 \%$ prostate size decrease and $50 \%$ reduction of total PSA level after 6 to 12 months of continuous treatment

This article is protected by copyright. All rights reserved. 
[4,11,12]. In 2012, the French Authority "Haute Autorité en Santé" recommended 5-ARI in second line treatment after failure of a-blockers and phytotherapy [13].

\section{OBJECTIVE}

The objective of the CANARI study was to assess, among a population of men with medical treatment licensed for symptomatic BPH, the association between 5-ARI use and PCa according to Gleason score $(<8$ or $\geq 8)$, compared to other medical treatments.

The present paper focuses on describing design, matching process, its results and the planned statistical analysis.

\section{State of the question and unsolved issues}

Considering firstly the involvement of testosterone and DHT in the development of PCa, and secondly that 5-ARI inhibit the testosterone conversion in DHT, Thompson et al. have investigated, in the PCPT (Prostate Cancer Prevention Trial) randomized controlled trial (RCT), the finasteride effect on the PCa risk reduction among healthy men (normal digital rectal examination (DRE) and PSA level $\leq 3 \mathrm{ng} / \mathrm{ml}$ ) during a 7-year study period [14]. Andriole et al., in the REDUCE (Reduction by Dutasteride of prostate Cancer Events) RCT, investigated the dutasteride effect in a population of men at risk of PCa (elevated PSA level with a previous PCa suspicion leading to a prostate biopsy) in a 4-year study [15]. Whereas both trials showed a relative risk overall reduction of PCa with 5-ARI when compared to placebo, PCPT showed that, after 7-year period, $6.4 \%$ of the men treated by finasteride had Gleason score 7 to 10 tumours (versus $5.1 \%$ in the placebo group, $P=0.005$ ), and REDUCE showed 12 tumours with Gleason score 8-10 in dutasteride group versus 1 in the placebo group during years 3 and $4(P=0.003)$. These trials gave rise to the question of 5 -ARI role in high grade PCa tumours (Gleason score $\geq 7$ ).

This article is protected by copyright. All rights reserved. 
Two other trials gave some information but had different population of interest and different outcomes. In CombAT (Combination of Avodart and Tamsulosin Trial) RCT, Roehrborn et al. have investigated the dutasteride effect, alone or in combination with tamsulosin, when compared to tamsulosin monotherapy on symptoms improvement or time to BPH surgery, in symptomatic moderate to severe BPH men; the risk of PCa was investigated as an adverse event [16]. A significant relative risk reduction of $\mathrm{PCa}$ was observed with dutasteride, alone $(37 \% ; 95 \% \mathrm{Cl}, 6-57 \%)$ or in combination with tamsulosin (43\%; $95 \% \mathrm{Cl}, 15-62 \%)$; the repartition of the different Gleason score between the three arms was described but not statistically analysed: numerically, over the 4-year study, less Gleason score 7 and 8-10 tumours are counted up in the dutasteride alone group (respectively, 8 and 14) and in combination group (respectively, 7 and 5) than in the tamsulosine group (respectively, 11 and 16). In REDEEM (reduction by dutasteride of clinical progression events in expectant management) RCT, Fleshner et al. investigated in low grade PCa patients with active surveillance the effect of dutasteride on the rate of cancer progression (number of cores' biopsy involved, Gleason pattern score of $\geq 4$, need of medical therapy) compared to placebo [17]: dutasteride significantly decrease the progression of the disease (HR $0.62,95 \% \mathrm{Cl} 0.43-0.89$ ). Two patients $(1 \%)$ in dutasteride group and 3 patients $(2 \%)$ in placebo group had Gleason score 8 tumours, in the final biopsy assessment.

Considering the potential signal from PCPT and REDUCE trials, Murtola et al. used patients' data from the third screening round of the Finnish Prostate Cancer Screening Trial (part of European Randomized Study of Prostate Cancer Screening) [18] which assessed whether screening could reduce PCa mortality: with a cohort approach, they investigated the effect of finasteride on the PCa incidence in BPH men compared to non-users coming from general population [19]. They observed no increased risk of high grade PCa (Gleason 7-10) in men receiving finasteride (hazard ratio, HR $1.33 ; 95 \% \mathrm{Cl} 0.77-2.30$ ) without consideration of duration of use; conversely an increased incidence of high grade tumours was observed $(\mathrm{HR} 2.61 ; 95 \% \mathrm{Cl}, 1.06-6.45)$ among finasteride users for longer than 4 years.

This article is protected by copyright. All rights reserved. 
In a nationwide Sweden population based case-control study, Robinson et al. selected their cases in the National Prostate Cancer Registry: no significant association was found between a Gleason score 8-10 tumour and an exposure to 5-ARI (compared to no treatment), whatever the duration of exposure period [20].

In Preston et al. study comparing 'ever' versus 'never user of 5-ARI' among a cohort of 38058 United States male health professionals ('ever' as 'never' could be treated by $\alpha$-blockers), authors failed to confirm the risk of high grade tumours (adjusted HR for Gleason score 8-10: 0.97, 95\% Cl, 0.64-1.46; adjusted HR for Gleason score $\geq 7: 1.07,95 \% \mathrm{Cl}, 0.79-1.45)$ [21].

Whereas PCPT and REDUCE trials have investigated the use of 5-ARI in primary prevention of PCa in men without BPH and showed a potential safety signal, observational studies failed to confirmed it. However, in all studies except CombAT, comparator groups were non-treated BPH patients in some studies $[19,20]$, or controls issued from general population. An approach using medically treated $\mathrm{BPH}$ as a comparator group could be more relevant to investigate more in depth the signal.

Some weaknesses have to be taken into account in these previous studies, limiting the results interpretation. First, detection bias is evoked for some reasons: 1/ some biopsies were pre-planned whereas others were made in front of clinical symptoms or biological criteria; 2 / impact of 5ARI on prostate size: as regard EAU recommendations, contrary to $\alpha$-blockers, 5-ARI are prescribed in enlarged prostate, lead to prostate size reduction and less surgery for acute urinary retention (4); the faster need to surgery and by extension the prostate sample pathologist analyse could lead to detect more promptly a potential PCa in $\alpha$-blockers treated patients compared with 5-ARI patients. 3/ Most studies used a comparative group with non-treated patients, assuming that some patients could be good healthy and need less clinic and biologic monitoring of their prostate than treated patients or than patients non-symptomatic BPH or without bothersome LUTS. Second, a lack of powerful appeared in some studies considering the low number of high grade PCa. Third, the definition of high grade PCa was different according to the study with a Gleason score 7 or 8 cut-off.

This article is protected by copyright. All rights reserved. 
Hence, results of available studies are potentially biased or not built to investigate the risk of PCa in BPH patients. Considering this question as a safety issue, undertake a randomized clinical trial is not appropriate. Furthermore, the time to PCa diagnosis is thought to be around 4 years. Large observational real-life study appears more relevant considering 1) sufficient power, 2) comparator group involving other BPH patients in order to limit indication bias when comparing 5ARI, 3) biopsies made in front of clinical or biological data and not pre-planned in order to limit detection bias.

\section{Feasibility of the study}

The challenge of our study concerned the fact that PCa registry does not exist in France, as well as pathology laboratories registry. Solution was found, linking, for the first time in France, SNIIRAM (Système National d'Information Inter-Régimes de l'Assurance Maladie) and a local 'Pathology laboratories database' where Gleason scores were obtained. SNIIRAM collects all individualized and health care claims reimbursed by the French National Health Insurance covering of about 65 million individuals $(97.5 \%$ of the French population) $[22,23]$. However no further details as regards nonreimbursed drugs, biological or clinical data are available in this database. Using SNIIRAM for medical purposes is controlled by law and linkage has to be approved by CNIL (Commission Nationale de I'Information et des Libertés): each file is also secondarily rendered pseudo-anonymous before its export so that the return to the initial nominal information is not possible. The local 'Pathology laboratories database' was built thanks to involvement of all Brittany path labs ensuring completeness of collection of prostate examination results; Professor Nathalie Rioux-Leclercq coordinates Brittany path labs network which allowed gathering and building up this database. Each of the nine path lab collected nominative results of prostate examination (positive and negative results) and send us a pseudo-anonymous file with a table presentation. Each table contained the name of path lab, a local identification number of the path examination, patient birth date, dates of prostate sampling, dates of reception of prostate samples in the path lab, and Gleason score in case

This article is protected by copyright. All rights reserved. 
of positive result. After data handling and management, we merged all tables in a unique file to constitute the 'pathology laboratories database'.

In France, $\mathrm{BPH}$ prevalence is $>30 \%$ among men of general population, and $45 \%$ of French men with prevalent cancers have a PCa [1,24]. Among male population in Brittany (around 1.5 million), standardized incidence of PCa reaches 150 per 100.000 men in 2011; incidence of high grade PCa (Gleason score $\geq 8$ ) was estimated to $13 \%$ (497 high grade PCa among 3635 case of PCa) in 2008$2009(23,24)$.

As for sample size, based on a $20 \%$ frequency of exposure to 5-ARi among the targeted population, a 1:5 case-to-control ratio and a significance level of 0.05 , the required sample size to ensure a $80 \%$ power is the following when comparing 5-ARI exposure between high grade PCa as cases and controls: 588 subjects (98 cases and 490 controls) to detect an odds-ratio of 2.0, 696 subjects (116 cases and 580 controls) to detect an odds-ratio of 1.9 and 840 subjects (140 cases and 700 controls) to detect an odds-ratio of 1.8. These calculations do not take into account matching, which will tend to increase power in an unknown manner.

Considering these aspects and that nationwide data collection from all French path labs was infeasible, we chose to link the two databases focusing on Brittany region that ensured the required sample size.

Legal authorization was obtained from CNIL: n DR-2014-084.

\section{METHODS}

\section{Study design}

CANARI study is a case-control study nested within a cohort of medically treated BPH patients (source population). Cases were patients with incident PCa and controls were patients free of PCa.

This article is protected by copyright. All rights reserved. 


\section{Data sources}

Two data sources have been used: 1/ We used nationwide SNIIRAM database to identify subjects who had a residency located in Brittany (in 2010-2011) and who met other selection criteria (see 'Case' section below); once identified, all healthcare claims (including drug delivery, hospitalisation discharge diagnosis, and chronic diseases identified through full coverage reimbursement registration) were collected wherever they were provided, hence, we thought we had no loss to follow-up and adequately captured all relevant events.; 2/ Pathology laboratories database which gives Gleason score (in case of positive result), a proxy of PCa aggressiveness.

\section{Source population}

Cases and controls came from a source population constituted of men $\geq 18$ years-old, affiliated to the French Health System, living in Brittany, who have at least one reimbursement of any pharmacologic treatment licensed for BPH (5-ARI monotherapy and in association, $\alpha$-blockers, and phytotherapy (Appendix 1)) between January $1^{\text {st }}, 2010$ and December $31^{\text {st }}, 2011$. For those subjects, all SNIIRAM data from January $1^{\text {st }}, 2010$ to December $31^{\text {st }}, 2013$ were extracted.

Patients with history of PCa before December $31^{\text {st }}, 2011$ were excluded (see below for PCa definition; of note we also checked for reimbursement of androgen deprivation therapy or surgery for orchiectomy to further identify a history of PCa, Appendix 1).

\section{Cases}

Thanks to SNIIRAM database, cases were identified as having a PCa diagnosis between January $1^{\text {st }}$, 2012 and December $31^{\text {st }}, 2013$, using ICD-10 codes C61 or D40.0 as hospitalisation discharge diagnosis or either an inscription on LTD list (Appendix 1). After linking of the databases, the PCa status was confirmed when we found at least one prostate examination with Gleason score in the Pathology laboratories database. The index date of PCa was established as the first date with a Gleason score obtained on a positive histological prostate examination (prostate biopsy, 
prostatectomy, prostate resection or any medical act leading to prostate sample; see Appendix 1) in Pathology laboratories database. A low grade PCa was defined by a Gleason score $<8$ and high grade PCa with a Gleason score $\geq 8$.

\section{Controls}

Thanks to SNIIRAM database, controls were identified as patients free of PCa (neither ICD-10 codes C61 or D40.0 for hospitalisation discharge diagnosis nor inscription on LTD list, nor any reimbursement of androgen deprivation therapy or surgery for orchiectomy). To each case, we randomly allocated 5 controls who were still alive when case was diagnosed, matched on year of birth, and on month where a delivery of a pharmacologic treatment licensed for BPH was first observed.

\section{Matching}

The linkage of path labs data and SNIIRAM database was made thanks to 2 keys: (1) month and year of birthday; (2) date (Month Day Year) of prostate sampling in SNIIRAM database, and date of reception of prostate sample (and if lacking the date of prostate examination) in Pathology laboratories database. Linkage was realized by a deterministic matching.

More in depth, in SNIIRAM database, we identified dates of prostate sampling for PCa cases and tend to match them with date of reception of prostate samples in Pathology laboratories database. To allow matching, we firstly relaxed the delay up to 3 days between date of prostate sampling and date of sample reception in path lab (mainly due to days off in week-end); secondly, for the remaining non-matched cases, we relaxed the delay up to 4 days. In case of several candidates for matching we checked the consistency of the geographic location between the hospital where prostate sampling was done and path labs. In case of several prostate examinations for one patient, we chose the first which gave a Gleason score; all the previous and later prostate examinations were not taken into consideration in the analysis.

This article is protected by copyright. All rights reserved. 


\section{Statistical analysis}

PCa is a composite outcome, consisting of high grade or low grade cancer. Association between PCa and 5-ARI exposure is expected to be different whenever low grade or high grade cancer was considered. An interaction term between exposure and cancer grade will be introduced in a logistic model in order to allow different association strength according to the considered individual outcome (low or high grade cancer) and to test homogeneity across these individual components of the composite outcome [27].

Univariate and multivariate analysis while adjusting for comorbidities (chronic obstructive pulmonary disease [COPD], use of treatment for diabetes mellitus, lipid-lowering drug use, obesity), number of prostate examination (prostate biopsy, transurethral resection...) and number of PSA measurement will be performed. Comorbidities and PSA measurement are identified through SNIIRAM database, thanks to ICD-10 codes, pharmacologic classes' codes (ATC codes) or biological acts codes (see Appendix1). Main analysis focuses on high grade PCa; all PCa and low grade PCa will be considered as secondary outcomes. We will consider BPH treatment as binary variable: ‘5-ARI users', i.e. 5-ARI alone (finasteride or dutasteride) or combined with another pharmacologic treatment for BPH, and 'other treatments' ( $\alpha$-blockers or phytotherapy, alone or combined together, without 5-ARI). Main analysis aims to compare 5-ARI ever users versus 5-ARI never users but the following exposures will also be considered for secondary analyses: 1) spliting 5-ARI into finasteride, dutasteride or both and 2) spliting 5-ARI according to cumulative duration of use before the index date to the previous available information: less than 1 year, [1-2] and $\geq 2$ years. Cases and their matched controls who started 5-ARI within a year before index date are deemed not of interest for cumulative exposure time analysis because PCa is present but latent in the year before diagnosis; in this case, cancer could not be related to 5-ARI exposure.

Results will be summarized using odds ratios with their $95 \%$ confidence intervals and associated $p$ values. They will be performed using the LOGISTIC procedure of the SAS software (SAS Institute Inc,

This article is protected by copyright. All rights reserved. 
Cary, NC), with a STRATA statement in order to take into account matching between cases and controls.

\section{RESULTS}

Linking our two databases, we succeeded to identify 859 cases of PCa according to their Gleason score: 119 had Gleason score $\geq 8$ and 740 Gleason score $<8$. We identified 4295 controls, 862 (20.1\%) of whom received 5-ARI. Among cases, 191 (22.2\%) received 5-ARI and 668 (77.8\%) received $\alpha$-blockers or phytotherapy.

More in depth as regard feasibility and results of matching process, our source population, in SNIIRAM database, concerned 74596 men, living in Brittany, who have at least one reimbursement of any pharmacologic treatment licensed for BPH between the January $1^{\text {st }}, 2010$ and December $31^{\text {st }}$, 2011. 'Pathology laboratories database' (data collected from 9 path labs in Brittany) contains 13796 prostate examinations with positive (PCa diagnosis) and negative (no PCa diagnosis) results, irrespective of BPH diagnosis, performed between January $1^{\text {st }}, 2012$ and December $31^{\text {st }}, 2013$ (See flow-chart).

In SNIIRAM database, we identified 1055 cases of PCa diagnosed between January $1^{\text {st }}, 2012$ and December $31^{\text {st }}, 2013$, who had 1623 prostate samplings (all types included). Most patients had 1 or 2 prostate samplings (respectively, 574 and 402 cases of PCa) (Figure 1).

This article is protected by copyright. All rights reserved. 


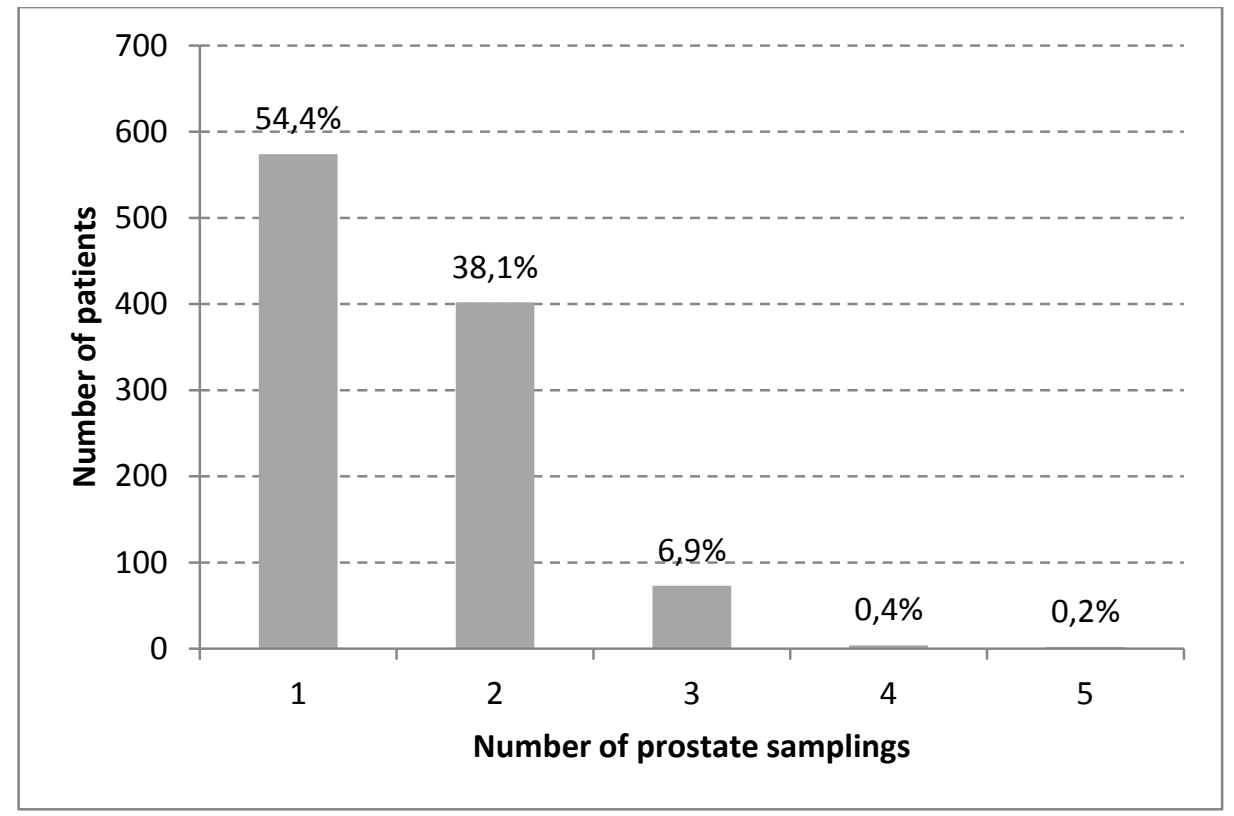

Figure 1. Number of patients with number of prostate samplings in SNIIRAM database.

By a deterministic approach, we matched 1275 prostate samplings shared by SNIIRAM and Pathology laboratories database: the 348 remaining prostate samplings concerned patients whose dates of prostate samplings (SNIIRAM) and dates of prostate examination (Pathology laboratories) were too distant.

We then checked matching consistency: from 1275 matched samplings, 1245 were retained concerning 905 patients with PCa (See flow-chart) because for 30 cases there were an inadequacy between sampling and examination as regards geographic area. Then, 46 patients who had no positive prostate examination results were excluded (for these patients a coding error of PCa in SNIIRAM database was possible, or the prostate sample performed later, with positive examination, has been sent in a path lab outside of Brittany). Eventually, 859 patients who had at least one prostate positive examination were analysed considering the first Gleason score for grading.

This article is protected by copyright. All rights reserved. 


\section{DISCUSSION}

We herein demonstrate the feasibility of matching SNIIRAM database to a path lab aggregated and pseudo-anonymous database through a deterministic process, then making 859 cases of PCa with Gleason score available for further statistical analysis. Contrary to previous studies which have used data from cancer registries or unique personal identity for matching databases, our goal was a bit more challenging, as we had to deal with two pseudo-anonymous databases, and path lab results coming from partitioned and heterogeneous databases. In Murtola et al. study [19], they used the Finnish Cancer Registry and the prescription database of Social Insurance Institution of Finland (SII). In a Swedish study [20], authors used the Swedish Cancer Register and the Swedish Prescribed Drug Register, with a linkage using the unique personal identity number assigned to each Swedish resident. In Preston et al. study [21], patients' medical and diseases data were directly coming from men Health Professionals themselves, via a mailed baseline questionnaire.

This study has some strength, including the large cohort size and a population based design. The matching process allowed the identification of 859 cases among 1055 patients identified with PCa in SNIIRAM database. We used drug claims for eligibility at cohort entry and for exposure categorisation; claims were collected timely and prospectively; hence recall bias did not apply and misclassification on exposure was minimised and non-differential. All subjects sought medical attention for symptomatic BPH which justify drug prescription; we then thought confounding by indication and detection bias were minimised. Lastly, thanks to SNIIRAM database, we had no attrition bias.

Among limits, we focused on data collected in Brittany path labs because nationwide data collection appeared infeasible. Secondly, prostate examinations were not centrally reviewed, considering moreover a revision of Gleason grading system in the meantime [28]. Thirdly, we do acknowledge potential residual confounding as we had indeed no information on prostate volume and body mass index nor on some behavioural risk factors, family status or level of education, but such adjustment did not seem to change the results in previous studies $[19,20]$.

This article is protected by copyright. All rights reserved. 
The topic of the potential high risk of PCa in BPH patients has to be put in perspective: indeed, the above listed studies have suggested that oral treatment of a benign disease could be associated with cancer and notably with a high grade process. It could be perceived as an unfair situation by subjects looking for the care of a benign disease and PCa is not anodyne as regards care, costs, utilities, quality of life and survival. Literature suggested that high risk PCa patients received the most resource-intensive treatments that induced the highest direct cost [29]: whereas in low risk PCa, total costs ranging from around $\$ 12,800$ at 5 years to around $\$ 17,300$ at 15 years, in high risk PCa, they ranging from around $\$ 33,600$ at 5 years to around $\$ 83,400$ at 15 years. As regards the lifetime direct costs and quality-adjusted life-years (QALY) for all management options, it appeared that for low risk patients, androgen suppression was the least costly strategy $(\approx \$ 18,450)$ and conferred the most QALY (12.5 years) when compared with active treatments. For high risk patients, radical prostatectomy was the least costly strategy $(\approx \$ 97,950)$ with a modest more QOL $(9.0$ years) when compared with intensity modulated radiotherapy.

To conclude, CANARI study aimed to compare for the first time, 5-ARI to other medical treatments in symptomatic BPH patients to investigate the risk of PCa. Considering some limits, previous published studies have not solved this question. Giving an answer is a major challenge as Gleason score is needed along with a large sample size. Despite partitioned and heterogeneous databases, we succeeded in matching them to SNIIRAM database. This result gives some perspective to further work using SNIIRAM database as its crucial enrichment is achievable though not straightforward.

\section{REFERENCES}

1 Costa P, Ben Naoum K, Boukaram M, et al. [Benign prostatic hyperplasia (BPH): prevalence in general practice and practical approach of French general practitioners. Results of a study based on 17,953 patients]. Prog Urol 2004;14:33-9.

2 Lukacs B. Management of symptomatic BPH in France: who is treated and how? Eur Urol 1999;36 Suppl 3:14-20.

3 Richard F, Lukacs B, Jardin A, et al. [Results of an epidemiologic surgery carried out with men 5080 years of age to study urinary disorders, quality of life and sexual function]. Progr Urol 2001;11:250-63.

This article is protected by copyright. All rights reserved. 
4 Oelke M, Bachmann A, Descazeaud A, et al. EAU guidelines on the treatment and follow-up of non-neurogenic male lower urinary tract symptoms including benign prostatic obstruction. Eur Urol 2013;64:118-40.

5 Descazeaud A, Barry Delongchamps N, Cornu J-N, et al. [Guide dedicated to general practitioner for the management of lower urinary tract symptoms related to benign prostatic hyperplasia]. Progr Urol 2015;25:404-12.

6 Gratzke C, Bachmann A, Descazeaud A, et al. EAU Guidelines on the Assessment of Nonneurogenic Male Lower Urinary Tract Symptoms including Benign Prostatic Obstruction. Eur Urol 2015;67:1099-109

7 Roehrborn CG. Three months' treatment with the alpha1-blocker alfuzosin does not affect total or transition zone volume of the prostate. Prostate Cancer Prostatic Dis 2006;9:121-5

8 Roehrborn CG, Siami P, Barkin J, et al. The effects of combination therapy with dutasteride and tamsulosin on clinical outcomes in men with symptomatic benign prostatic hyperplasia: 4-year results from the CombAT study. Eur Urol 2010;57:123-31

9 McConnell JD, Bruskewitz R, Walsh P, et al. The effect of finasteride on the risk of acute urinary retention and the need for surgical treatment among men with benign prostatic hyperplasia. Finasteride Long-Term Efficacy and Safety Study Group. N Engl J Med 1998;338:557-63.

10 McConnell JD, Roehrborn CG, Bautista OM, et al. The long-term effect of doxazosin, finasteride, and combination therapy on the clinical progression of benign prostatic hyperplasia. $\mathrm{N}$ Engl J Med 2003;349:2387-98.

11 Rittmaster RS, Norman RW, Thomas LN, et al. Evidence for atrophy and apoptosis in the prostates of men given finasteride. J Clin Endocrinol Metab 1996;81:814-9

12 Naslund MJ, Miner M. A review of the clinical efficacy and safety of 5alpha-reductase inhibitors for the enlarged prostate. Clin Ther 2007;29:17-25

13 Haute Autorité en Santé (HAS). Synthèse d'avis de la commission de la transparence (Avodart, Combodart, Chibro-Proscar) - Avis favorable au remboursement, uniquement en deuxième intention dans le traitement de l'hypertrophie bénigne de la prostate (septembre 2012). Published Online First: September 2012.www.has-sante.fr/portail/jcms/c_1353462

14 Thompson IM, Goodman PJ, Tangen CM, et al. The influence of finasteride on the development of prostate cancer. N Engl J Med 2003;349:215-24.

15 Andriole GL, Bostwick DG, Brawley OW, et al. Effect of dutasteride on the risk of prostate cancer. N Engl J Med 2010;362:1192-202.

16 Roehrborn CG, Andriole GL, Wilson TH, et al. Effect of dutasteride on prostate biopsy rates and the diagnosis of prostate cancer in men with lower urinary tract symptoms and enlarged prostates in the Combination of Avodart and Tamsulosin trial. Eur Urol 2011;59:244-9.

17 Fleshner NE, Lucia MS, Egerdie B, et al. Dutasteride in localised prostate cancer management: the REDEEM randomised, double-blind, placebo-controlled trial. The Lancet 2012;379:1103-11.

18 Määttänen L, Auvinen A, Stenman UH, et al. European randomized study of prostate cancer screening: first-year results of the Finnish trial. Br J Cancer 1999;79:1210-4

This article is protected by copyright. All rights reserved. 
19 Murtola TJ, Tammela TL, Määttänen L, et al. Prostate cancer incidence among finasteride and alpha-blocker users in the Finnish Prostate Cancer Screening Trial. Br J Cancer 2009;101:843-8.

20 Robinson D, Garmo H, Bill-Axelson A, et al. Use of $5 \alpha$-reductase inhibitors for lower urinary tract symptoms and risk of prostate cancer in Swedish men: nationwide, population based casecontrol study. BMJ 2013;346:f3406

21 Preston MA, Wilson KM, Markt SC, et al. $5 \alpha$-Reductase inhibitors and risk of high-grade or lethal prostate cancer. JAMA Intern Med 2014;174:1301-7.

22 Palmaro A, Moulis G, Despas F, et al. Overview of drug data within French health insurance databases and implications for pharmacoepidemiological studies. Fundam Clin Pharmacol 2016;30:616-24.

23 Tuppin P, Pestel L, Samson S, et al. [The human and economic burden of cancer in France in 2014, based on the Sniiram national database]. Bull Cancer (Paris) 2017;104:524-37.

24 Institut National Du Cancer (INCa). Les cancers en France - Edition 2015 - Ref : ETKFRANCE16. 2016.http://www.e-cancer.fr/Expertises-et-publications/Catalogue-des-publications/Lescancers-en-France-Edition-2015 (accessed 28 Oct 2016).

25 Incidence et mortalité des cancers en Poitou-Charentes (janvier 2013) - Registre des cancers. http://www.ors-poitou-charentes.org/pdf/kasP7WProstate2-13.pdf (accessed 28 Oct 2016).

26 Colonna M, Danzon A, Delafosse $P$, et al. Cancer prevalence in France: time trend, situation in 2002 and extrapolation to 2012. Eur J Cancer 2008;44:115-22

27 Pogue J, Devereaux PJ, Thabane L, et al. Designing and analyzing clinical trials with composite outcomes: consideration of possible treatment differences between the individual outcomes. PloS One 2012;7:e34785.

28 Epstein JI, Zelefsky MJ, Sjoberg DD, et al. A Contemporary Prostate Cancer Grading System: A Validated Alternative to the Gleason Score. Eur Urol 2016;69:428-35.

29 Sanyal C, Aprikian AG, Cury FL, et al. Management of localized and advanced prostate cancer in Canada: A lifetime cost and quality-adjusted life-year analysis. Cancer 2016;122:1085-96.

This article is protected by copyright. All rights reserved. 
Appendix 1.

\begin{tabular}{|c|c|c|c|c|c|}
\hline Variable & Drugs / ATC codes & $\begin{array}{l}\text { LTD } \\
\text { codes }\end{array}$ & CCMA & ICD-10 & $\begin{array}{l}\text { Biological } \\
\text { codes }^{\mu}\end{array}$ \\
\hline $\begin{array}{l}\text { Benign prostate hypertrophy } \\
\text { (BPH) }\end{array}$ & $\begin{array}{l}\text { - a-blockers monotherapy: G04CA01, G04CA02, } \\
\text { G04CA03, G04CA04 } \\
\text { - 5ARI: G04CB*: } \\
\text { finasteride: G04CB01; dutasteride: G04CB02 } \\
\text { - 5ARI in association with a-blockers: G04CA52 } \\
\text { - Other drugs for PBH, phytotherapy: G04CX* }\end{array}$ & & & $\mathrm{N} 40^{*}$ & \\
\hline $\begin{array}{l}\text { Prostate cancer } \\
\text { (PCa) }\end{array}$ & $\begin{array}{l}\text { Androgen Deprivation Therapy (ADT): } \\
\text { - GnRH Agonist: LO2AE* } \\
\text { - GnRH antagonist: LO2BX02 } \\
\text { - Antiandrogene: LO2BB*, G03HA* } \\
\text { Abiraterone : L02BX03 } \\
\text { - Enzalutamide : L02BBO4 }\end{array}$ & 30 & $\begin{array}{l}\text { - Orchiectomy: } \\
\text { JHFA010 } \\
\text { - Brachytherapy: } \\
\text { JGNL001 } \\
\text { - Radiation for PCa: } \\
\text { ZZNL* in patients } \\
\text { with ICD-10 C61 } \\
\text { and exclusion of all } \\
\text { ICD-10 codes of } \\
\text { cancer } \\
\\
\text { - Prostate } \\
\text { biopsy sample: } \\
\text { JGHB02 } \\
\text { JGHD001 } \\
\text { JGHJ001 } \\
\text { JGHJ002 } \\
\text { JGFA005 } \\
\text { JGFA009 } \\
\text { JGFA014 } \\
\text { JGFA015 } \\
\text { JGQX001 } \\
\text { JGHB001 } \\
\text { JGFA007 } \\
\text { JGFA016 } \\
\text { JDFA019 } \\
\text { JDFA020 } \\
\text { JDFA021 } \\
\text { JDFA022 } \\
\text { JDFA023 } \\
\text { JDFA024 } \\
\text { JDFA025 } \\
\text { JGFA006 } \\
\text { JGFA011 } \\
\text { JGFC001 }\end{array}$ & C61*, D40.0 & \\
\hline $\begin{array}{l}\text { Chronic obstructive pulmonary } \\
\text { disease }\end{array}$ & & & & J44* & \\
\hline Diabetes mellitus & A10A, A10B & & & & \\
\hline Obesity & & & & E66* & \\
\hline PSA measurement & & & & & 7318,7320 \\
\hline
\end{tabular}

$\mu$ Using the French classification 'nomenclature des actes biologiques et médicaux' (NABM).

This article is protected by copyright. All rights reserved. 
Figure 1. Flow chart

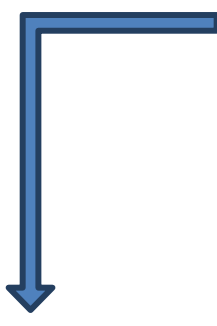

\begin{tabular}{|c|c|}
\hline $\begin{array}{c}1055 \text { patients } \\
\text { diagnosed with prostate cancer } \\
\text { between } 01 / 01 / 2012 \text { and } 31 / 12 / 2013\end{array}$ & $\begin{array}{l}1623 \text { prostate samplings according to } \\
\text { SNIIRAM database between } \\
01 / 01 / 2012 \text { and } 31 / 12 / 2013\end{array}$ \\
\hline
\end{tabular}
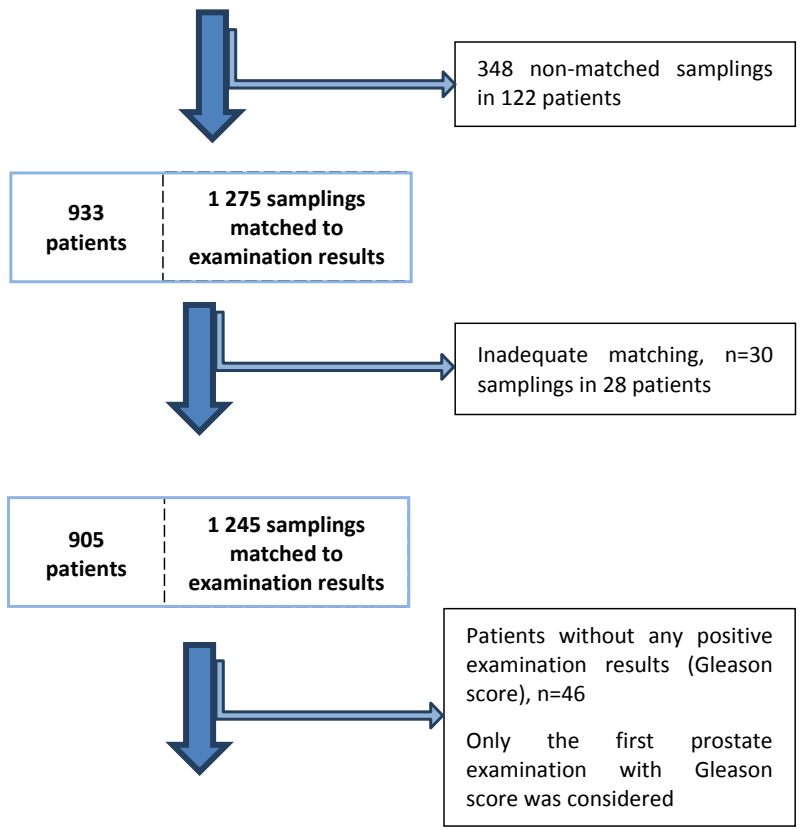

\begin{tabular}{|c|c|}
\hline 859 & 859 samplings \\
patients & matched to first \\
& positive \\
& examination result \\
\hline
\end{tabular}
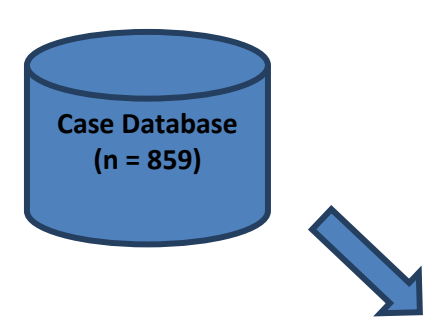

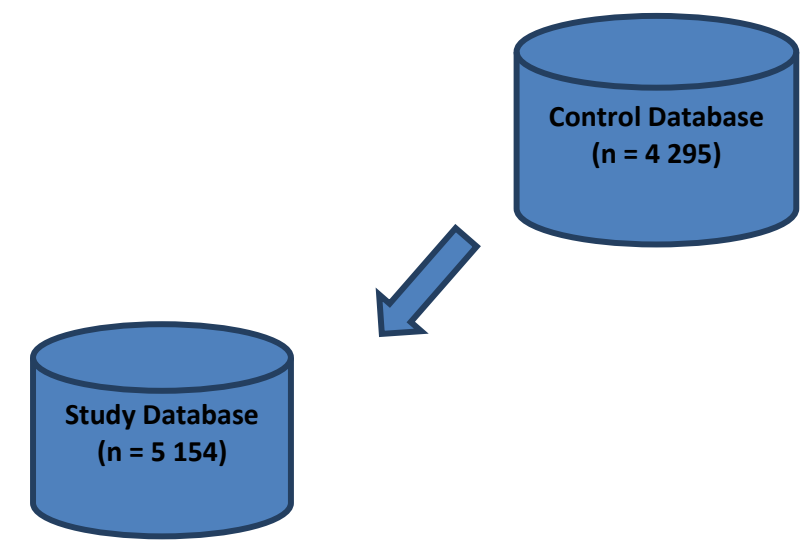

Patients without prostate cancer until December $31^{\text {st }}, 2013$ $n=67370$

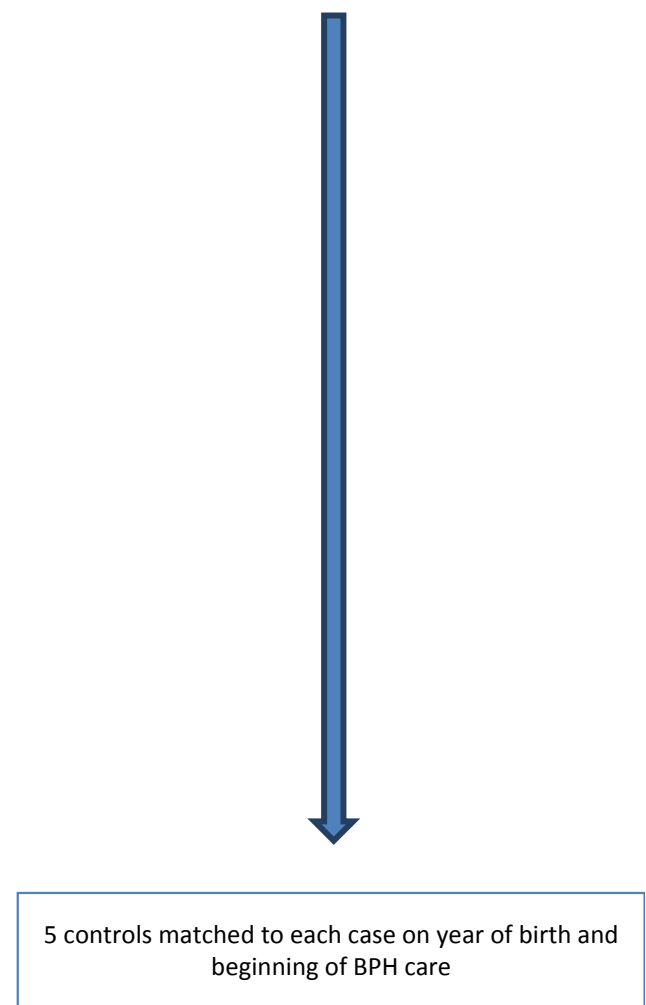

This article is protected by copyright. All rights reserved. 